\title{
Performance Evolution in Satellite Communication Networks Along with Markovian Channel Prediction
}

\author{
Kamal Harb ${ }^{1,2, *}$, F. Richard Yu ${ }^{1}$, Samir Abdul-Jauwad ${ }^{2}$ \\ ${ }^{1}$ Electrical En gineering Department, KFUPM University, Dhahran, 31261, Saudi Arabia \\ ${ }^{2}$ Department of Systems and Computer Engineering, Carleton University, 1125, Colonel By Drive, Ottawa, Ontario, Canada
}

\begin{abstract}
Augmenting accurate prediction of channel attenuations can be of immense value in improving the quality of signals athigh frequency for satellite communication networks. Such prediction of weather related attenuation factors for the impendingweather conditions based on the weather data and the Markovian theory are the main object of this paper. The paper also describes anintelligent weather a ware control system (IWACS) that is used to emp loy the predictions made from Markov model to ma intainthe quality of service (QoS) in channels that are impacted by rain, gaseous, cloud, fog, and scintillation attenuations. Based onthat, a three dimensional relationship is proposed among estimated atmospheric attenuations, propagation angle, and predictedrainfall rate $\left(R_{\mathrm{pr}}\right)$ at a given location and operational frequency. This novel method of predicting weather characteristicssupplies valuable data for mitigation planning, and subsequently for developing an algorithm to iteratively tune the IWACS byadaptively selecting appropriate channel frequency, modulation, coding, propagation angle, transmission power level, and datatransmission rate to improve the satellite's system performance. Some simulation results are presented to show the effectiveness of the proposedscheme.
\end{abstract}

Keywords Intelligent Weather Aware Control System (IWACS), Markov Model, Quality of Service (QoS), Satellite Communications, Signal to Noise Ratio (SNR), WeatherPrediction

\section{Introduction}

Recently, satellite based communication networks at high frequency bands have been rapidly expanding. These high frequencyoperations have enabled a wide variety of available and potentialapplications and services including communications, navigation,tele-medicine, remote sensing, distributed sensors networks, and wireless access to the internet. However, high frequencyoperations are prone to excessive digital transmissionerrors due to atmospheric attenuations[1]-[[8].

Control systems attempt to minimize the effect ofattenua tionby adjusting the transmission parameters and signal characteristics.However, exciting system rely on total attenuationin actuating the transmission control.Consequen tly, the control of transmission parameters have been less than the optimal as the detail knowledge of occurrence probabilities fordifferent impairments would have been missing. Knowing expectedimpairments separately for different attenuation factors, more specifically the weather factors, would help us utilizethe most appropriate methods for mitigating impairments withmechanisms like up-link power control, adaptive coding, antenna beam shaping,

* Corresponding author:

kharb@kfupm.edu.sa (Kamal Harb)

Published online at http://journal.sapub.org/jwnc

Copyright (C) 2012 Scientific \& Academic Publishing. All Rights Reserved. ansite diversity[9],[10]. Therefore, improve quality of service $(\mathrm{QoS})$ provisioning?[11].

The major atmospheric and weather related factors in signalattenuation are rain fade, gaseous absorption, cloud attenuation, and tropospheric scintillation. Among them, the rainattenuation (RA), also known as rain fade, is the dominantcause of signal impairment, especially at frequencies higherthan $10 \mathrm{GHz}$ and small aperture antennas such as Very SmallAperture Terminal (VSAT) and Television Receive Only types(TVRO)[2],[12]-[17].

International Teleco mmunication Union - Radiocommun ications(ITU-R) maintains a large database for probability ofprecipitation and other parameters. It provides mathematicalequations and analytical approaches to estimate rainfall rate(RR) and different atmospheric attenuations around the worldfrom these data[18]. However, ITU-R techniques were developed in view of finding the average conditions and boundaryconditions, which are more useful for the design of controlsystem and less for the operation of those systems. Moreover,ITU-R techniques were developed at a time when the high frequencyoperations above $\mathrm{Ku}$ band, where losses become really significant,were not expected. Consequently, there was a greatroom to first improve the ITU-R techniques to maintain them accurateat higher frequency operations and second, to decouplethem from the fifteen years average data provided by ITUR.Instead, if we make ITU-R techniques work with real-timeweather data, those techniques could 
help us achieve better operation,as they were helping us with the system design inthe past[13],[14],[17], and[19].

Some of the prior work in the area include[20], where RRis predicted by using weather radar reflection data instead ofground based measurement. Paper[21] presented a methodcalled two level Markov model to pred ict multi-path fading ofsignals. Authors of[22]presented a method for RA predictionwhich yielded good results during low rain and low elevationangle. Authors in[24] presented fade duration prediction as a function of RA and frequency and used modelling of channelsto obtain signal attenuation due to clouds and precipitation.While[25] cited difficulty in approximating the lossesdue to limited availability of experimental data on clouds; $[26]$ cited problem in developing accurate models due to ambiguityof cloud water content and cloud extent limits. In[10], authorspresent prediction models and analytical techniques fora range of operational parameters involving low-margin, lowelevation angle, inclined geosynchronous, and low earth orbitsystems. The paper estimated rain and scintillation whileassuming gaseous attenuations as constant. These techniqueshave helped to mature the control systems in satellite communication.Due to new bandwidth and frequency requirements, the problems of attenuations due to various atmospheric factorshave come to receive increased level of prominence dueto increased operations at frequencies above $10 \mathrm{GHz}$. Theseproblems are articulated very well by[2],[3],[7], and[12].

In our past research work, we demonstrated that a bettercontrol of satellite signal parameters resulting in improvedsystem performance could be achieved by taking into accountthe major weather related contributors of signal attenuationseparately[16]. $\operatorname{In}[5]$ we demonstrated how estimation of RR, aswell as attenuation due to rain, gas, cloud, fog, and scintillation, could be measured. The methodology yielded greateraccuracy in estimating the weather related attenuation. Totalattenuation as well as constituent weather attenuations werecalculated for any rainfall conditions and for any elevation angle. However, this methodology relied on historical data collected by ITU-Rthat provided average rainfall per year for locations throughoutthe world based on statistical data collected over a decade[6].During the research, we realized that the estimations wouldhave helped tune channel parameters in real-time had the real-timemeasurements were used to gain a closer estimation of impendingweather conditions. The work reported in this paperwas inspired by that premise. As research thrusts were put to improveQoS on satellite based networks withthe use of intelligent prediction methods, the work presentedin this paper should be of significant interest to research anddevelopment community.This paper makes four major contributions towards improvingthe operation of satellite control systems and enhancing theperformance of satellite network systems. This is specificallytrue during severe weather condition and operations ofcommun icationc hannels above $\mathrm{Ku}$ band. The major contributions of the work are:
1. Migration of ITU-R techniques from the domain of the improvingdesign to the domain of improving the operation,

2. Application of Markov theory in real-time prediction ofweather and applying of those predictions in the forecastof atmospheric attenuation,

3. Improvement of ITU-R techniques in predicting rain, gas,cloud, fog, and scintillation attenuations more accuratelyat wide range of frequencies including $\mathrm{Ka}$ band and tomake them work at any propagation angle, and RRs,

4. An enhanced intelligent weather aware control system(IWACS) for achieving improved channel performance.

This paper is presented in five sections. Section 2 describesprediction of different weather attenuation factors based onMarkovian modelling of weather characteristics. Section 3 describescalculation of rain, gaseous, cloud, fog, and scintillationattenuations which will be used by IWACS in decisionmaking. Section 4 presents simulation environment and implementationof IWACS, results and discussions. Finally, weconclude this study in Section 5.

\section{Prediction of Channel Characteristics}

This section describes the behaviour of RA at high frequency and proposes a method for better estimating channel attenuation in weather impacted satellite networks. The RA is computed, based on predicted rainfall rate $\left(R R_{p r}\right)$, which itself is predicted by using Markov theory[27] along with ITU-R models and bi-linear interpolation[28],[29]. The method predicts RR at any location on earth, for a wide range of propagation angles and frequencies. The $\mathrm{RR}_{\mathrm{pr}}$ values are then used toadjust the control parameters and,therefore, help improve the QoS in communication channels.

\subsection{The Rainfall Rate Prediction}

In this section, we present prediction of rainfall rate usingMarkov theory on the time series of weather data. For that reason, weather is considered a discrete random process thatcan assume a set of finite states. Further, it is assumed that thechange from one state to another is a random discrete step withcertain transition probability $(p)$, whose value is derived fromstatistical properties of the system.

\subsubsection{Classification of Rain}

For the purpose of explaining to the reader the application ofMarkov modelling for predicted rainfall rate, a specific locationis chosen where we divided rainfall rate ranges into five classes starting from zero $\mathrm{mm} / \mathrm{hr}$ up to the highest rainfall rate as follows:

a. Class A: from zero up to but less than $1 \mathrm{~mm} / \mathrm{hr}$.

b. Class B: from 1 up to but less than $4 \mathrm{~mm} / \mathrm{hr}$.

c. Class C: from 4 up to but less than $8 \mathrm{~mm} / \mathrm{hr}$.

d. Class D: from 8 up to but less than $14 \mathrm{~mm} / \mathrm{hr}$.

e. Class E: values greater than $14 \mathrm{~mm} / \mathrm{hr}$.

The discrete time interval chosen in this study was one 
hour. The reason being that environment should supplyweather data in one hour intervals. However, the method canbe applied for finer grain intervals given that weather data forshorter intervals are available.

The approach in grouping total rain conditions into classifiedblocks has been depicted in Figure 1. This classificationin actual data provides the basis for the data required to applyMarkovian theory in the prediction of rainfall rate[8].

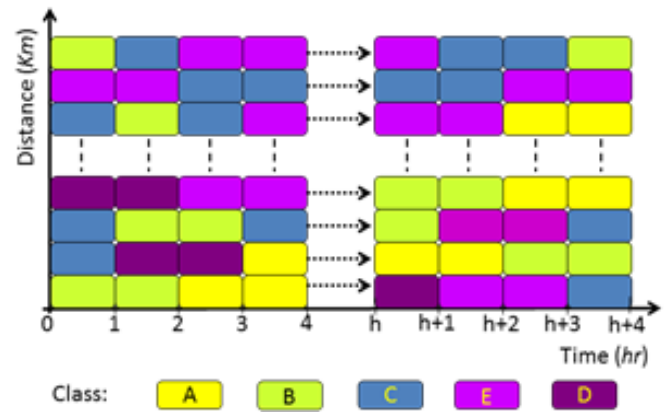

Figure 1. Presentation of the five rainfall rate classes

To make the classification of rainfall rate to better reflectlocal statistical weather patterns, two parameters can be adjusted:

a. Periodicity of rainfall rate: Instead of selecting one hourinterval, periodicity in minutes or hours could be used.The smaller the sampling period, the more instantaneouswill be the rainfall rate values especially when dealingwith rapidly changing weather conditions.

b. Number of classes: Instead of five, the number of classes could be decreased or increased according to the variation of rainfall rate history for that location. More classes means more computational time with finer granularity of control.

\subsubsection{Markov Model Implementation}

I- Weight of Transition Probability Matrices:

Different weights are assigned to each Markov state, zero order(present state), first order (previous state), and second order(previous to previous state), as defined in Markov
Chaintheory. There exist no direct formulas for calculating theseweights and it needs iterative search involving trial and error.The weight values need to be validated over many sets of data.

The resulting weight vector is denoted as:

$$
[\mathrm{W}]_{(1 \times 3)}=[\mathrm{W}(0) \mathrm{W}(1) \mathrm{W}(2)],
$$

where $\mathrm{W}(0), \mathrm{W}(1)$, and $\mathrm{W}(2)$ represent weight assignedto present, previous, and previous to previous intervals, respectively, as shown in Figure 2. Each weight in (1)(1) has adifferent unique value and the largest value will belong to thepresent weight $\mathrm{W}(0)$ and so on for the other weights. Also,these weights are positive numbers and their summation is equal to one. This research came to conclude that there exista set of weight that work very well for all possible sets oftransition probability matrices describe below.

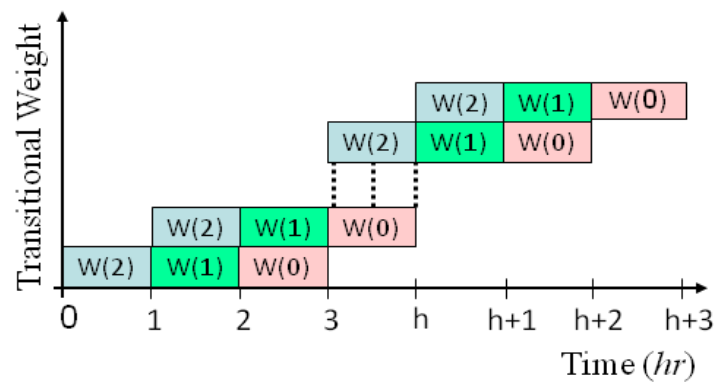

Figure 2. Presentation of the three different weights

\section{II- Transition Probability:}

The transition probabilities and classification of rain aredirectly correlated. The transition probabilities are theprobabilities of moving from given state to another state.

In Markov Chain theory, the probability of a discrete event to remain in state $\mathrm{x}$ is denoted as $P(x)$. In this representation, independent chains without any memory of past state are called zero-order Markov Chains. The transition probability matrix of zero-order Markov Chaintheory $\left[P_{0}\right]$ for the five presented classes is, thus, represented as follows:

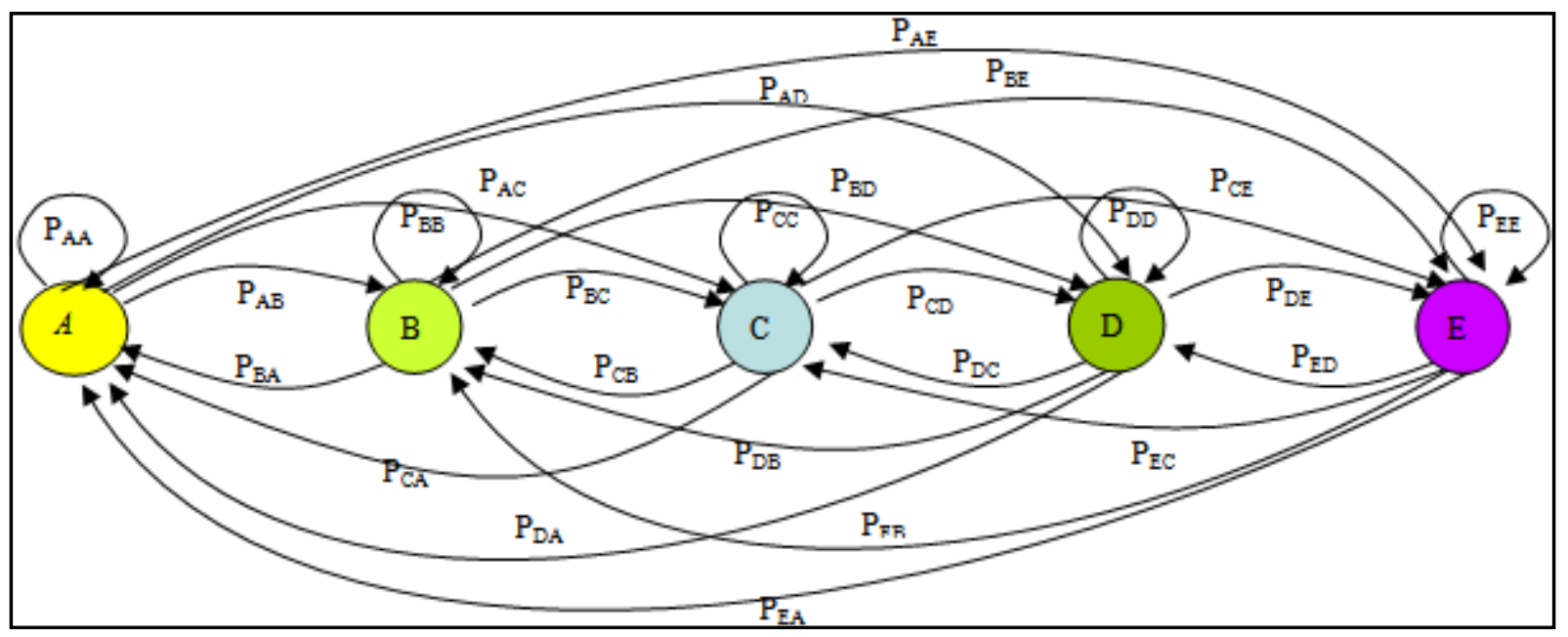

Figure 3. First Order Markov Chain model with transition probabilities for switching among different states 


$$
\left[P_{0}\right]_{(1 \times m)}=\left[\begin{array}{llll}
P_{A} & P_{B} & P_{C} & P_{D} P_{E}
\end{array}\right]
$$

Then the process consisting of a finite number of states with known probabilities $\mathrm{P}(\mathrm{x}, \mathrm{y})$ of transition from state $\mathrm{y}$ to state $\mathrm{x}$ is considered a first order Markov Chain[27],[30]-[31]. The transition probability matrix of the first-order Markov Chain for the five classes is shown below in(3). These transitions are depicted in a pictorial form in Figure 3 and can be represented by:

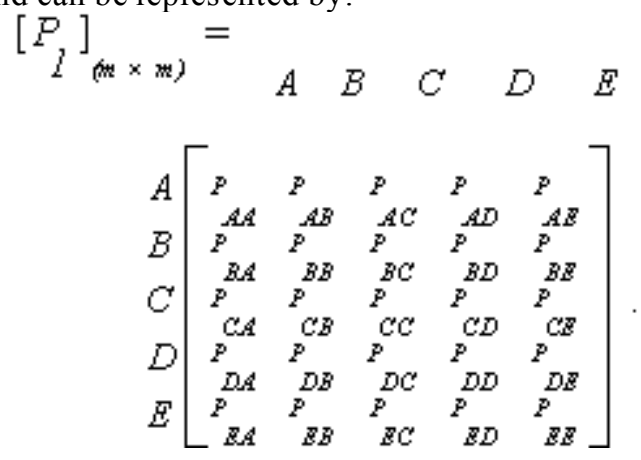

Similarly, the transition probability matrix of the second-orderMarkov Chain theory $P(z \mid x y)$ for the five classes is presentedin (4).

$$
\begin{aligned}
& \left.{ }_{2}{ }_{2}\right](m \times m)= \\
& \begin{array}{lllll}
A & B & C & D & E
\end{array} \\
& A A\left[\begin{array}{lllll}
P_{A A A} & P_{A A B} & P_{A A C} & P_{A A D} & P_{A A E}
\end{array}\right]
\end{aligned}
$$

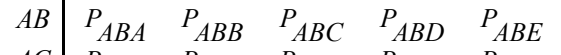

$$
\begin{aligned}
& \begin{array}{l|lllll}
A C & P_{A C A} & P_{A C B} & P_{A C C} & P_{A C D} & P_{A C E}
\end{array}
\end{aligned}
$$

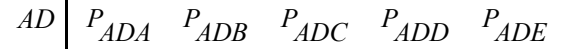

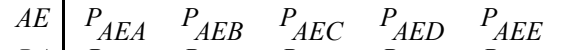

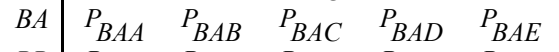

$$
\begin{aligned}
& \begin{array}{llllll}
B B & P_{B B A} & P_{B B B} & P_{B B C} & P_{B B D} & P_{B B E} \\
P_{B C A} & P_{B C B} & P_{B C C} & P_{B C D} & P_{B C E}
\end{array} \\
& \begin{array}{l|lllll}
B C & P_{B C A} & P_{B C B} & P_{B C C} & P_{B C D} & P_{B C E} \\
B D & P_{B D A} & P_{B D B} & P_{B D C} & P_{B D D} & P_{B D E}
\end{array} \\
& \begin{array}{llllll}
B D & P_{B D A} & P_{B D B} & P_{B D C} & P_{B D D} & P_{B D E}
\end{array}
\end{aligned}
$$

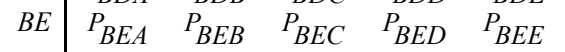

$$
\begin{aligned}
& \begin{array}{llllll}
C A & P_{C A A} & P_{C A B} & P_{C A C} & P_{C A D} & P_{C A E}
\end{array} \\
& \begin{array}{llllll}
C B & P_{C B A} & P_{C B B} & P_{C B C} & P_{C B D} & P_{C B E}
\end{array} \\
& \begin{array}{llllll}
C C & P_{C C A} & P_{C C B} & P_{C C C} & P_{C C D} & P_{C C E}
\end{array}
\end{aligned}
$$

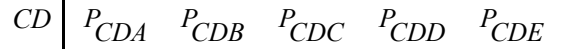

$$
\begin{aligned}
& \begin{array}{llllll}
C E & P_{C E A} & P_{C E B} & P_{C E C} & P_{C E D} & P_{C E E}
\end{array}
\end{aligned}
$$

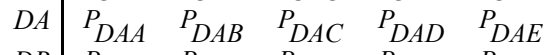

$$
\begin{aligned}
& D B \quad \begin{array}{lllll}
P_{D B A} & P_{D B B} & P_{D B C} & P_{D B D} & P_{D B E}
\end{array} \\
& D C \quad \begin{array}{lllll}
P_{D C A} & P_{D C B} & P_{D C C} & P_{D C D} & P_{D C E}
\end{array} \\
& \begin{array}{llllll}
D D & P_{D D A} & P_{D D B} & P_{D D C} & P_{D D D} & P_{D D E}
\end{array} \\
& \text { DE } \begin{array}{lllll}
P_{D E A} & P_{D E B} & P_{D E C} & P_{D E D} & P_{D E E} \\
P_{E A A} & P_{E A B} & P_{E A C} & P_{E A D} & P_{E A E}
\end{array} \\
& \text { EA } \begin{array}{lllll}
P_{E A A} & P_{E A B} & P_{E A C} & P_{E A D} & P_{E A E}
\end{array} \\
& \begin{array}{llllll}
E B & P_{E B A} & P_{E B B} & P_{E B C} & P_{E B D} & P_{E B E}
\end{array}
\end{aligned}
$$

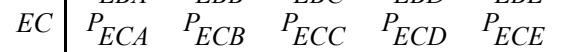

$$
\begin{aligned}
& \begin{array}{l}
E D \\
E E
\end{array}\left[\begin{array}{lllll}
P_{E D A} & P_{E D B} & P_{E D C} & P_{E D D} & P_{E D E} \\
P_{E E A} & P_{E E B} & P_{E E C} & P_{E E D} & P_{E E E}
\end{array}\right]
\end{aligned}
$$

The characteristics of these transition probability matricesare such that the entries for each column vectors in (2), (3), and (4) are positive numbers. The sum of the elements of eachrow in the matrices is one. The columns represent probability vectors, which are the stochastic values for transition. The transition probabilities are dependent on statistical pattern of rain at a particular geography and climate.

Note that, $m$ and $n$ represent the number ofrows and columns, respectively.

\subsubsection{Pred icted Rainfall Rate}

The value of predicted rainfall rate for the immediately followingdiscrete time period is computed based on probability andweight combinations. These combinations present a specialmodule of weather prediction of different weights assigned toeach transition probability matrix along with Markov Chain oforder $\phi$, where $\phi$ is fin ite and equal to 2 in our case. Thus,the prediction of the future state is dependent on the present,previous, and previous to previous states and is independent of the other earlier states[[8].

Given that the zero [P0], first [P1], and second order [P2] transition probability matrices with the weights assigned to each matrix (W(0)), (W(1)), and (W(2)), respectively. The predicted rainfall rate values can be computed as follows:

$\mathrm{PW}(1)=\mathrm{W}(0) \cdot \mathrm{P} 0(1)+\mathrm{W}(1) \cdot \mathrm{P} 1(\mathrm{~m}, 1)+\mathrm{W}(2) \cdot \mathrm{P} 2(\mathrm{n}, 1), \mathrm{PW}(2)$

$=\mathrm{W}(0) \cdot \mathrm{P} 0(2)+\mathrm{W}(1) \cdot \mathrm{P} 1(\mathrm{~m}, 2)+\mathrm{W}(2) \cdot \mathrm{P} 2(\mathrm{n}, 2)$,

$\mathrm{PW}(3)=\mathrm{W}(0) \cdot \mathrm{P} 0(3)+\mathrm{W}(1) \cdot \mathrm{P} 1(\mathrm{~m}, 3)+\mathrm{W}(2) \cdot \mathrm{P} 2(\mathrm{n}, 3)$,

$\mathrm{PW}(4)=\mathrm{W}(0) \cdot \mathrm{P} 0(4)+\mathrm{W}(1) \cdot \mathrm{P} 1(\mathrm{~m}, 4)+\mathrm{W}(2) \cdot \mathrm{P} 2(\mathrm{n}, 4)$,

$\mathrm{PW}(5)=\mathrm{W}(0) \cdot \mathrm{P} 0(5)+\mathrm{W}(1) \cdot \mathrm{P} 1(\mathrm{~m}, 5)+\mathrm{W}(2) \cdot \mathrm{P} 2(\mathrm{n}, 5)$.

Where the numbers $(1,2,3,4$, and 5$)$ represent the five classes(A, B, C,D, and E) shown in Figure 1.

$[\mathrm{P} 0]$ represents the rowcorresponding to the present state. [P1] represents the row correspondingto the transition from the last state to the presentstate. [P2] represents the row corresponding to the transitionfrom the last-to-last to the last state and then to the presentstate. In our specific case, the $m$ can be any value rangingfrom 1 to 5 and $n$ can be any value ranging from 1 to 25 accordingto the previous and previous to previous weather state,respectively.

Also, $P W s$ presented in (5)can be written in asimple mathematical form as:

$\mathrm{PW}(\mathrm{u})=\mathrm{W}(0) \cdot \mathrm{P}_{0}(\mathrm{u})+\mathrm{W}(1) \cdot \mathrm{P}_{1}(\mathrm{~m}, \mathrm{u})+\mathrm{W}(2) \cdot \mathrm{P}_{2}(\mathrm{n}, \mathrm{u}) \cdot(2)$

Where $u$ ranges from 1 to 5 and $P W$ represents the probabilityweight values of the five existing classes $(A, B, C$, $D$, and $E$ ), thus:

$$
\begin{aligned}
{[\mathrm{PW}]_{(\mathrm{u} \times 1)} } & =[\mathrm{PW}(1) \mathrm{PW}(2) \mathrm{PW}(3) \mathrm{PW}(4) \mathrm{PW}(5)] \\
& =\left[\mathrm{PW}_{\mathrm{A}} \mathrm{PW}_{\mathrm{B}} \mathrm{PW}_{\mathrm{C}} \mathrm{PW}_{\mathrm{D}} \mathrm{PW}_{\mathrm{E}}\right] .
\end{aligned}
$$

Therefore, the predicted rainfall rate $\left(\mathrm{RR}_{\mathrm{pr}}\right)$ will be belongingto the class that has the maximum probability weight of $P W$ vector collected from (7).

Figure 4 shows a demonstration for the effectiveness of ourmethod for predicting rainfall rate. At the beginning, we usedrandomly generated values of rainfall rate to determine theweights and probability matrix elements for our model[15].

These values were then tested against rainfall rate valuesthat were collected by Environment Canada for almost twomonth duration at SouthWest of King City using weather radarnear Toronto, Ontario, Canada. We applied our methodologyto predict the future state out of past states. The 
prediction dataobtained using our method and the measured rainfall data fromEnvironment Canada are provided in Figure 4 and in Table 1.

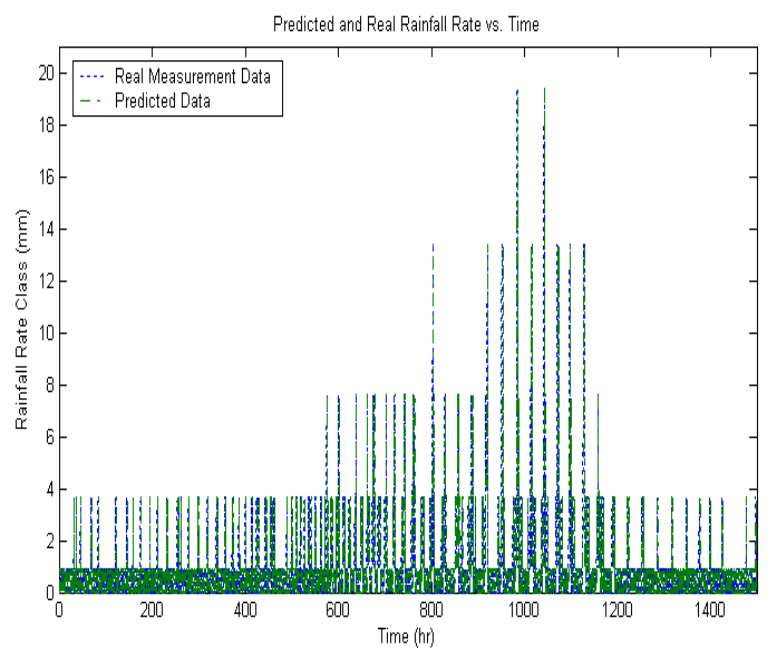

Figure 4. Comparison of actual and predicted rainfall rate values at South West of King City

Table 1. Comparison of Accurate and Predicted Rainfall Rate Data at Different Time

\begin{tabular}{|c|c|c|c|}
\hline $\begin{array}{r}\text { Time } \\
{[h r]}\end{array}$ & $\begin{array}{l}\text { Accurate } \\
\text { Time Data } \\
{[\mathrm{mm} / \mathrm{hr}]}\end{array}$ & $\begin{array}{c}\text { Predicted } \\
\text { Data } \\
{[\mathrm{mm} / \mathrm{hr}]}\end{array}$ & $\begin{array}{l}\text { Different Between } \\
\text { Both Results } \\
{[\mathrm{mm} / \mathrm{hr}]}\end{array}$ \\
\hline 1 & 0 & 0 & 0 \\
\hline 3 & 0 & 0 & 0 \\
\hline 4 & 0 & 0 & 0 \\
\hline 80 & 0 & 0 & 0 \\
\hline 170 & 0 & 0 & 0 \\
\hline 200 & 0 & 0 & 0 \\
\hline 210 & 1 & 0 & 1 \\
\hline 220 & 0 & 0 & 0 \\
\hline 330 & 0 & 0 & 0 \\
\hline 338 & 1 & 1 & 0 \\
\hline 350 & 0 & 0 & 0 \\
\hline 510 & 1 & 1 & 0 \\
\hline 610 & 1 & 1 & 0 \\
\hline 620 & 0 & 0 & 0 \\
\hline 640 & 0 & 0 & 0 \\
\hline 650 & 1 & 1 & 0 \\
\hline 780 & 1 & 1 & 0 \\
\hline 790 & 0 & 0 & 0 \\
\hline 880 & 1 & 1 & 0 \\
\hline 890 & 0 & 0 & 0 \\
\hline 970 & 0 & 0 & 0 \\
\hline 1071 & 8 & 8 & 0 \\
\hline 1098 & 4 & 4 & 0 \\
\hline 1103 & 0 & 1 & 1 \\
\hline 1104 & 1 & 1 & 0 \\
\hline 1126 & 8 & 4 & 4 \\
\hline 1127 & 8 & 8 & 0 \\
\hline 1137 & 1 & 1 & 0 \\
\hline 1148 & 0 & 0 & 0 \\
\hline 1152 & 0 & 0 & 0 \\
\hline 1155 & 1 & 1 & 0 \\
\hline 1190 & 1 & 1 & 0 \\
\hline 1192 & 1 & 1 & 0 \\
\hline 1429 & 0 & 0 & 0 \\
\hline
\end{tabular}

Note thatonly small numbers of samples are presented in thetable to keep it readable and that the prediction matches closelywith the measured results.

We conclude that, the Markovian Chain has promising applicationin effectively predict ing the future weather result in statisticalterms. The results are astoundingly accurate. Therefore, our methodology for predict ing ra infall rate can be applied underdifferent weather conditions at any given location on earth.

\subsubsection{The Values of Weights and Transition Probabilities}

The values of the weight matrix as defined in (1) and the transitionprobabilities as defined in (2), (3), and (4)were obtainedthrough an extensive exercise of iterative adjustments and theirtest of validity on rainfall rate data. At the end, the study notonly revealed a set of workable values but they also revealed the following behaviours:

1- For a given set of transition probabilities, there is a correspondingweight that gives the best prediction of rainfallrate in Markov Chain theory.

2- Studies done over actual rain data revealed that the fivestates model developed here gives extremely reliable predictionof rain with the following values of weights (W's)are:

$$
[W]_{(1 \times 3)}=\left[\begin{array}{lll}
0.495 & 0.335 & 0.170
\end{array}\right]
$$

and transition probabilities ( $P$ 's $)$ are:

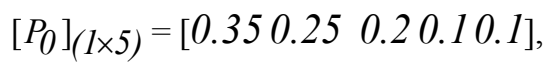

$$
\left[P_{1}\right]_{(1 \times 5)}=A \quad B \quad C \quad D \quad E
$$

and

$$
\begin{gathered}
A \\
\vdots \\
E
\end{gathered}\left[\begin{array}{ccccc}
0.43 & 0.33 & 0.2 & 0.04 & 0 \\
\vdots & \vdots & \vdots & \vdots & \vdots \\
P_{E A} & P_{E B} & P_{E C} & P_{E D} & P_{E E}
\end{array}\right]
$$

$$
\begin{aligned}
& {\left[P_{2}\right]_{(5 \times 25)}=} \\
& \begin{array}{lllll}
A & B & C & D
\end{array} \\
& \begin{array}{c}
A A \\
\vdots \\
E E
\end{array}\left[\begin{array}{ccccc}
0.45 & 0.37 & 0.14 & 0.03 & 0.01 \\
\vdots & \vdots & \vdots & \vdots & \vdots \\
P & P & P & P & P \\
E E A & E E B & E E C & E E D & E E E
\end{array}\right]
\end{aligned}
$$

The full set of values could be obtained by contacting theauthors.

3- When rain rate classification as done in Section 2.1.1 isaltered to better suite different locations on earth, the coefficientsmentioned above will change. However, thevalues listed here will give good starting values for theiterative process of finding the new values.

Notice that, the weights and the transition probability matricesvalues are selected initially based on the statistical investigationof historical field of data collected over several 
years. Wediscovered that the coefficient of the matrices and the weightsremain relatively stable alt- hough weather conditions vary significantly.Nevertheless, ome severe weather conditions notrecorded by the data analysed for this research could requiresomeadjustments.

Note that, we acknowledge the dependence of Markoviantheory in stochastic assumptions and the potential errors in estimatingthe weights and the coefficients of transition probability matrices. This is denoted especially for the fact that themethod assumes stationary weather within one discrete timeperiod; its prediction is nothing more than a practical approximation.Nevertheless, the test on the fields' data demonstratedhighly respectable results, yielding prediction values to containlow relative percentage error of $(\leq 9.9 \%)$ for the presentedfifteen hundred hours for rainfall rate.

\subsection{Migrating ITU-R Model from the Design Domain to the Operational Domain}

ITU-R technique for estimating environmental attenuations based on weather data collected over a decade and a half has served us well in system design because it is able to provide average and boundary conditions that a communication system would be subjected to. ITU-R provides not only the geographic parameters of a location, such as the height above the sea level and the average rain height as shown in Figure 5,but also the weather factors like probability of precipitation and mathematicalformula for estimating rainfall rate, and subsequentlyestimatingsignal attenuation due to rain, gas, cloud, fog, andscintillation. The knowledge of the attenuation servesuseful purpose in optimizing the design by finding the best combination of frequency, modulation,coding, and othertransmission and reception parameters for a given location in relative to other locations.

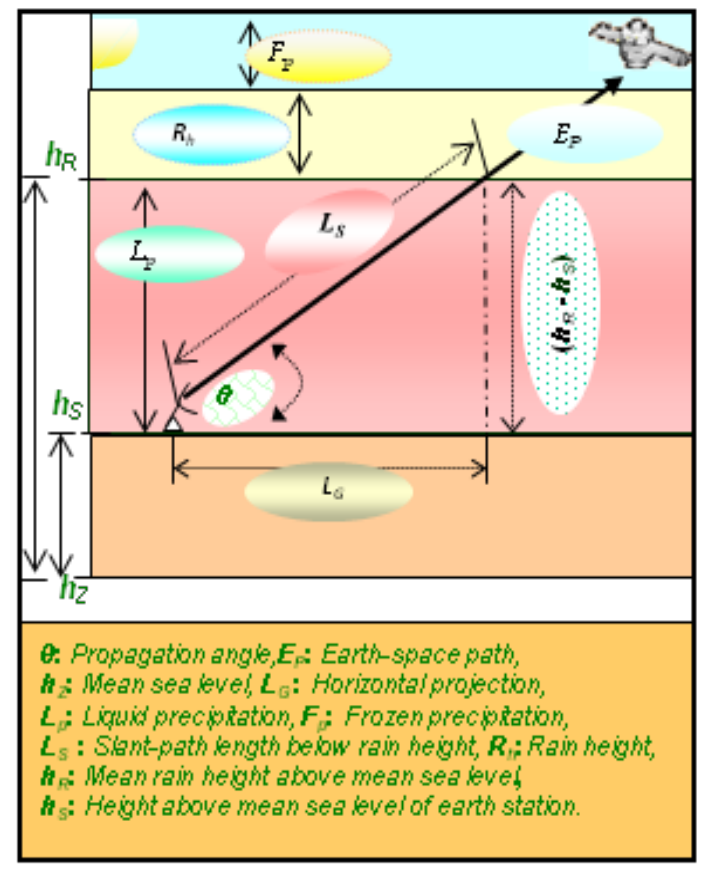

Figure 5. Earth-space path
The research work reported in this paper stemmed fromknowing that if these techniques were to be extended to estimatethe attenuations in a real-time environment, they wouldhave greatly served in the purpose of operating those designedsystems optimally by allowing selecting proper combination of controllable parameters. Therefore, the ITU-R methodologywas studied and extended to solve the problem of adapting thecontrol systems with instantaneous variations of weather attenuation.

We propose the use of Markov theory in estimatingthe weather condition for the immediately following timeperiodbased on the real-time data of immediately precedingperiods and the statistical probability of state changes. Subsequentexperiments demonstrated that the inclusion of Markovianprediction technique and its resulting data as an input to ITU-Rtechniques resulted in real-time prediction of weather attenuations.

The next enhancement made in ITU-R techniques was estimatingattenuation as a function of rainfall rate, propagationangle, and operational frequencies so that they hold true evenunder high frequency operation above Ku band. The outcomeof these changes was that they yielded highly accurate estimationof $R R$ and then that of rain, gaseous, fog, cloud, andscintillationattenuations. Such evolution in the ability to predict weather attenuation in real-time had direct consequencein improving the real-time control by enhancing theability toselect the signal parameters.

The following are the key benefits achieved by the proposedtechnique:

1. Better estimation of attenuation including high frequencyoperations.

2. Real-time estimation of RR. The prediction of $R R$ ismade by viewing the weather data from a moving windowof fixed time intervals and the impending rainfall rate isestimated based on current rate, previous rate, and previousto previous rate.

3. Calculation of attenuations based on the real-time estimationof RR.

4. Real-time signal adaptation to weather variation by selectingappropriate channel parameters.

\section{Calculation of Rain, Gaseous, Cloud,Fog, and Scintillation Attenuations}

In this paper, a new relationship model is proposed for estimatingvarious weather attenuations as a function of propagationangle, $\mathrm{RR}_{\mathrm{pr}}$, and frequency, for any derived geographic locationof ground terminals. This model results in three dimensionalgraphs which relates the attenuation, $\mathrm{RR}_{\mathrm{pr}}$, and propagationangle for a selected operational frequency, which may be anyvalue from 0 to $55 \mathrm{GHz}$. RA is the single greatest weatherdependent signal attenuation factor, which occurs in satellitenetworks largely due to signal absorption and scattering of incomingsignal. Fortunately rain forms only in the tropospherethat extends 
around sixteen kilometers from sea level whilethe satellites are located in geostationary orbit at 35,800 kmabove earth[6]. Therefore, exposing signal to rain attenuationonly during a small portion of its transmission path as shownin Figure 6.

Nevertheless as the frequency increase the losses increaseas shown in Table 2[32]-[35]. Even heavy rainfall of $10 \mathrm{~cm} / \mathrm{hr}$ seems to cause a small attenuation of $0.05 \mathrm{~dB} / \mathrm{km}$ with RF signalsat $2.4 \mathrm{GHz}$. The Ku band attenuation for the same rainfall,however, is approximately nine times that of C-band, andthus very substantial for it to be ignored[36], [37]. Therefore,estimating different atmospheric attenuations at regional or individualsites is important for improving control ofsatellite channel parameters especially when higher transmissionfrequencies are adopted to achieve greater transmissionrate through communication channels.

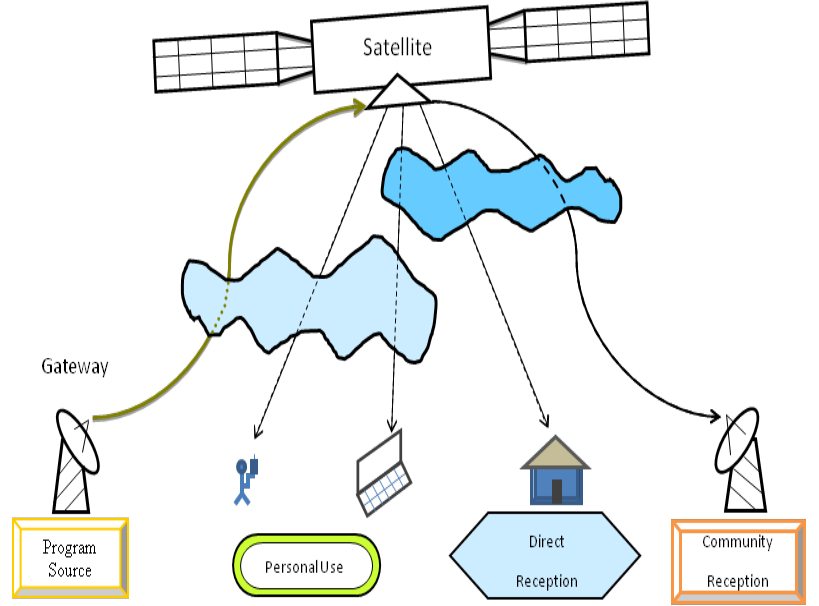

Figure 6. A satellite broadcast system in the presence of horrendous weather condition

Table 2. VSAT frequency spectrum allocation

\begin{tabular}{|c|c|c|c|c|}
\hline Band & $\begin{array}{c}\text { Frequency } \\
\mathrm{GHz}\end{array}$ & $\begin{array}{c}\text { Area } \\
\text { Foot-print }\end{array}$ & $\begin{array}{c}\text { Power } \\
\text { Delivered }\end{array}$ & $\begin{array}{c}\text { Rainfall } \\
\text { effect }\end{array}$ \\
\hline $\mathrm{C}$ & $3-7$ & Large & Low & Minimum \\
\hline $\mathrm{Ku}$ & $10-18$ & Medium & Medium & Moderate \\
\hline $\mathrm{Ka}$ & $18-31$ & Small & High & Severe \\
\hline
\end{tabular}

In this section a new technique for estimating channel attenuationsis presented. This technique, estimates constituentcontributors of total attenuation separately and extends it togive good approximations for a wide range of signal frequencies,propagation angle, and $R_{\mathrm{pr}}$. The technique uses ITU-Rcoeffic ients as shown in Figure 5 while estimating the attenuationat grid locations in a weather collection map that was used by ITU-R. Incases where the location of concern does not fall on the grid, abi-linear interpolation technique is then used to get the parameters $[5]$ ,[13].

Most of the formulas and variables presented in this sectionare direct evolutions from the ITU-R method with notify modifications and enhanced presentation for different weather parameters. We implemented these formulas and variablesto handle real-time data of the present one hour window and used the Markovian prediction that was presented earlier with proposed values of the matrices components to predict the data for the following period.

This section is devoted first, to predict constituent contributors of channel attenuation s eparately due to different weather variants, and then, to determine the total attenuation due to all of thefactors combined. Also, included in this section is the technique for calculatingthe signal to noise ratio (SNR) based onthese attenuations.

\subsection{Calculating Rain Attenuation (RA)}

The RA, represented as $\left(A_{r}\right)$, is predicted by using a set offunctions and solving them for different satellite-location dependentvalues. The values of RA are calculated as a functionof frequency $(f)$ and predicted rain fall rate $\left(\mathrm{RR}_{\mathrm{pr}}\right)$. The foundationalwork of this technique and its variables are explainedin[5], [14] and [38].

The key destination of this technique is that we start with anattenuation value at a known frequency $\left(f_{n}\right)$, and then estimatethe attenuation at one increment higher frequency $\left(f_{n+1}\right)$.Then using the attenuation at $\left(f_{n+1}\right)$, we find attenuation $\operatorname{at}\left(f_{n+2}\right)$, and so on. That is, once RA is known at any lowerfrequency, we will be able to compute RA at a higher frequency andcontinue the process until the maximum desiredfrequency is reached.

This iterative calculation is made using the following threeequations. Equation (12) establishes the relationship betweenRA and $\mathrm{RR}_{\mathrm{pr}}$ (see[13],[19]for full description).

Thesecond equation (13) establishes relationship between an intermediatevariable $\mathrm{H}$ with a known value of RA at a knownfrequency $\left(f_{n}\right)$. Then the next equation (14)calcu lates RA atthe next frequency $\left(f_{n+1}\right)$. This process is iteratively repeateduntil RA reaches the desired frequency.

The RA for different frequencies and $R_{\mathrm{pr}}$ values can beobtained from[13]:

$$
A_{r}\left(f_{n}, R R_{P}\right)=\gamma_{R}\left(f_{n}, R R_{P}\right) . L_{E}\left(f_{n}, R R_{P}\right) d B
$$

Also, for any specific frequency ranging from 7 to 55 GHzcan be obtained from:

$$
\begin{gathered}
H\left(\phi\left(f_{n}\right), \phi\left(f_{n+1}\right), A_{r}\left(f_{n}, R R_{p r}\right)\right)=1.12 \times 10^{-3} \\
\ldots \cdot\left(\phi\left(f_{n+1}\right) / \phi\left(f_{n}\right)\right)^{0.5}\left(\phi\left(f_{n}\right) A_{r}\left(f_{n}, R R_{p r}\right)\right)^{0.55} \\
A\left(f_{n+1}, R R_{p r}\right)=A_{r}\left(f_{n}, R R_{p r}\right) . \\
\left(\phi\left(f_{n+1}\right) / \phi\left(f_{n}\right)\right)\left(1-H\left(\phi\left(f_{n}\right), \phi\left(f_{n+1}\right), A_{r}\left(f_{n}, R R_{p r}\right)\right)\right) \\
A_{r}\left(\theta, R R_{p r}\right)=\gamma_{R}\left(\theta, R R_{p r}\right) \cdot L_{E}\left(\theta, R R_{p r}\right) d B(15
\end{gathered}
$$

Where $A_{r}\left(\theta, R R_{p r}\right)$ represents $\mathrm{RA}$ for a given value of $\mathrm{RR}_{\mathrm{pr}}$, and propagation angle $\theta$, as shown in Figure 7. As a reference, the variab les $L_{E}, \varphi$, and $\gamma_{R}$ are described in[13].

This method also has an added advantage by providinghigh CPU efficiency since we do not have to repeat the entirecalculation for each frequency ending with similar resultsto that for existing ITU-R. It is achieved by 
eliminating the accumulated errorwhen compared to that of existing approximated ITU-Rsolution[13].

The predicted values of RA at any desired location, for differentpropagation angles, $\mathrm{RR}_{\mathrm{pr}}$, and channel frequency, are important determinants in channel qualities. However, in orderto control the satellite channels efficiently, we also need to factorother parameters like gaseous, cloud, fog, and scintillationattenuations as described below.

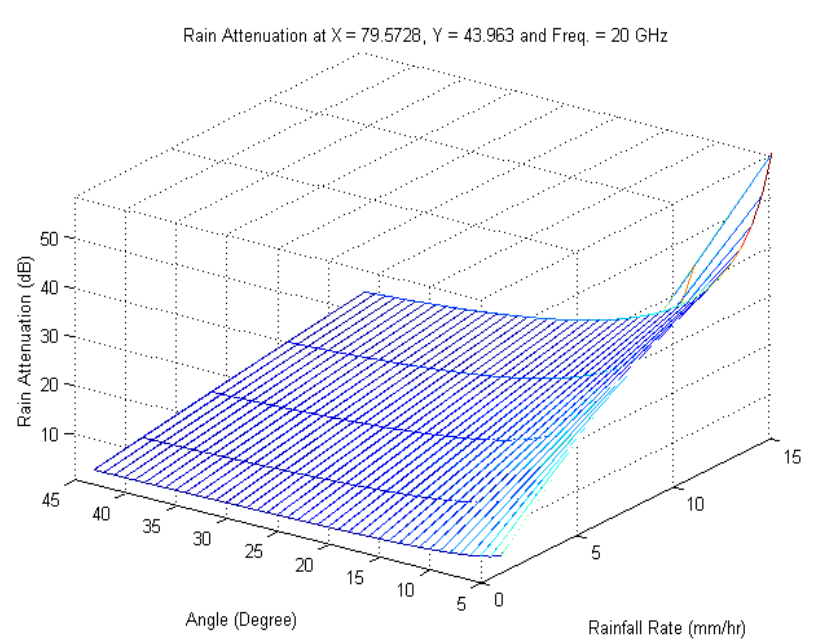

Figure 7. Rain attenuation at South West of King City

\subsection{Calculating Gaseous Attenuation}

In this section, an analytical method for estimating gaseousattenuation has been presented. This has been an extension ofthe methodology presented in ITU-R P. 676. The slant pathattenuation depends on various meteorological conditions createdby the distribution of temperature, pressure, and humidityalong the transmission path. Thus, the effective path lengthvaries with location, month of the year, height of the stationabove the sea level, and propagation angle. The gaseous attenuationis calculated using the following steps:

1. Specific attenuation for dry air $\left(\gamma_{\tau}\right)$

2. Specific attenuation for water vapour $\left(\gamma_{\mathrm{v}}\right)$

3. Equivalent path length for dry air $\left(h_{\tau}\right)$

4. Equivalent path length for water vapour $\left(h_{\mathrm{v}}\right)$.

ematical technique for obtaining the values of theseparameters is given below. The calculation of total gaseousattenuation $\left(A_{g}\right)$, then follows:

1. Specific Attenuation for the Dry A ir $\left(\gamma_{\tau}\right)$ :

The attenuation $(\mathrm{dB} / \mathrm{km})$ for the frequency $(f \leq 54 \mathrm{GHz})$ is given as:

$$
\begin{aligned}
& \phi\left(r_{p h}, r_{t}, a, b, c, d\right) \\
& =r_{p h}^{a} r_{t}^{b} \exp \left[c\left(1-r_{p h}\right)+d\left(1-r_{t}\right)\right]
\end{aligned}
$$

with

$$
\begin{gathered}
\xi_{1}=\varphi\left(r_{p h}, r_{t}, 0.0717,-1.8132,0.0156,-1.6515\right) \\
\xi_{2}=\varphi\left(r_{p h}, r_{t}, 0.5146,-4.6368,-0.1921,-5.7416\right)
\end{gathered}
$$

$$
\xi_{3}=\varphi\left(r_{p h}, r_{t}, 0.3414,-6.5851,0.2130,-8.5854\right)
$$

and

$$
\begin{aligned}
& \gamma_{\tau}= \\
& {\left[\frac{7.2 r_{t}^{2.8}}{f^{2}+0.34 r_{p}^{2} r_{t}^{1.6}}+\frac{0.62 \xi_{3}}{(54-f)^{1.16 \xi_{1}}+0.83 \xi_{2}}\right] f^{2} r_{p}^{2} \times 10^{-3},}
\end{aligned}
$$

2. Specific Attenuation for the Water vapour $\left(\gamma_{v}\right)$ :

The attenuation $\gamma_{\nu}(\mathrm{dB} / \mathrm{km})$ is given as:

$$
\begin{aligned}
\gamma_{w} & =\left\{\frac{3.98 \eta_{1} \exp \left[2.23\left(1-r_{t}\right)\right]}{(f-22.235)^{2}+9.42 \eta_{1}^{2}} g(f, 22)+\frac{11.96 \eta_{1} \exp \left[0.7\left(1-r_{t}\right)\right]}{(f-183.31)^{2}+11.14 \eta_{1}^{2}}\right. \\
& +\frac{0.081 \eta_{1} \exp \left[6.44\left(1-r_{t}\right)\right]}{(f-321.226)^{2}+6.29 \eta_{1}^{2}}+\frac{3.66 \eta_{1} \exp \left[1.6\left(1-r_{t}\right)\right]}{(f-325.153)^{2}+9.22 \eta_{1}^{2}} \\
& +\frac{25.37 \eta_{1} \exp \left[1.09\left(1-r_{t}\right)\right]}{(f-380)^{2}}+\frac{17.4 \eta_{1} \exp \left[1.46\left(1-r_{t}\right)\right]}{(f-448)^{2}} \\
& +\frac{844.6 \eta_{1} \exp \left[0.17\left(1-r_{t}\right)\right]}{(f-557)^{2}} g(f, 557) \\
& +\frac{290 \eta_{1} \exp \left[0.41\left(1-r_{t}\right)\right]}{(f-752)^{2}} g(f, 752) \\
& \left.+\frac{8.3328 \times 10^{4} \eta_{2} \exp \left[0.99\left(1-r_{t}\right)\right]}{(f-1780)^{2}} g(f, 1780)\right\} f^{2} r_{t}^{2.5} \rho \times 10^{-4}
\end{aligned}
$$

with

$$
\begin{gathered}
\eta_{1}=0.955 r_{p h} r_{t}^{0.68}+0.006 \rho, \\
\eta_{2}=0.735 r_{p h} r_{t}^{0.5}+0.0353 r_{t}^{4} \rho \\
g\left(f, f_{i}\right)=1+\left(\frac{f-f_{i}}{f+f_{i}}\right)^{2} .
\end{gathered}
$$

and

$$
h_{\tau}=\frac{6.1}{1+0.17 r_{p}^{-1.1}}\left(1+t_{1}+t_{2}+t_{3}\right)
$$

Where $p h$ : pressure $(h P a), r_{p h}=p h=1013, r_{t}=288 /(273+t)$, $\rho$ water-vapour density $\left(\mathrm{g} / \mathrm{m}^{3}\right), f$ : frequency $(\mathrm{GHz})$, and $t$ : mean temperature values $\left({ }^{\circ} \mathrm{C}\right)$, can be obtained from ITU-R P. 1510 when noadequate temperature data is available.

3. Equivalent Path Length for the Dry A ir:

The equivalent height of the dry air is given by:

$$
t_{1}=\frac{4.64}{1+0.066 r_{p h}^{-2.3}} \exp \left[-\left(\frac{f-59.7}{2.87+12.4 \exp \left(-7.9 r_{p h}\right)}\right)^{2}\right]
$$

Where

$$
\begin{aligned}
& t_{2}=\frac{0.14 \exp \left(2.12 r_{p h}\right)}{(f-118.75)^{2}+0.031 \exp \left(2.2 r_{p h}\right)} \\
& t_{3}=\frac{0.0114}{1+0.14 r_{p h}^{-2.6}} f \frac{-0.0247+10^{-4} f+1.61 \times 10^{-6} f^{2}}{1-0.0169 f+4.1 \times 10^{-5} f^{2}+3.2 \times 10^{-7} f^{3}}
\end{aligned}
$$

and

$$
h_{o} \leq 10.7 r_{p h}^{0.3}
$$

with the constraint that:

when $<70 \mathrm{GHz}$ :

4. Equivalent Path Length for the Water Vapour: For water vapour, the equivalent height for $f \leq 350 \mathrm{GHz}$ is: 


$$
\begin{aligned}
h_{v}= & 1.66\left(1+\frac{1.39 \sigma_{v}}{(f-22.235)^{2}+2.56 \sigma_{v}}\right. \\
& \left.\cdots+\frac{3.37 \sigma_{v}}{(f-183.31)^{2}+4.69 \sigma_{v}}+\frac{1.58 \sigma_{v}}{(f-325.1)^{2}+2.89 \sigma_{v}}\right)
\end{aligned}
$$

Where

$$
\sigma_{v}=\frac{1.013}{\left(1+\exp \left[-8.6\left(r_{p h}-0.57\right)\right]\right)}
$$

Notice that water vapour has resonance of $(22.235 \mathrm{GHz})$, (183.31 GHz), and (325.1 GHz)respectively and that attenuation changes with theamount of water vapour in the atmosphere.

- Calculating total gaseous attenuation inclined arrangements of station.

The above method calculates slant path attenuation for watervapour that relies on the knowledge of the profile of watervapourpressure (or density) along the attenuation path.

This section proposes a method to obtain the path attenuationbased on surface meteorological data using the cosecant lawfor a given propagation angle and $R_{\mathrm{pr}}$ as:

$$
A_{G a s}\left(\theta, R R_{p r}\right)=\frac{A_{\tau}+A_{v}\left(R R_{p r}\right)}{\sin \theta}
$$

where $A_{\tau}=h_{\tau} \gamma_{\tau}$ and $A_{v}=h_{v} \gamma_{v} d B$, and $\theta \leq 5^{\circ}$. Thus, the estimated gaseous values are computedat any desired location, for all ranges of propagation angle andRR $\mathrm{pr}_{\mathrm{pr}}$, and for any frequency as shown in Figure 8.

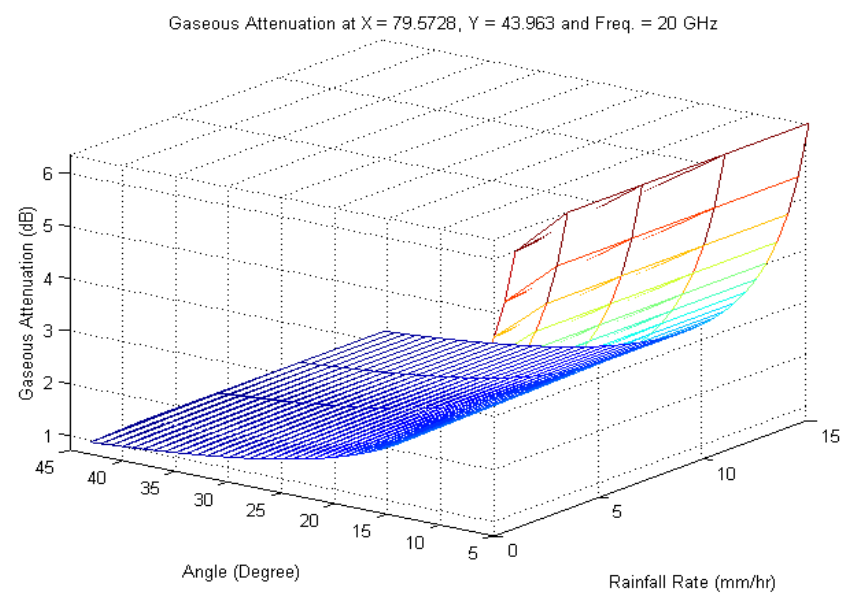

Figure 8. Gaseous attenuation at South West of King City

\subsection{Calculating Cloud and Fog Attenuations}

Cloud and fog can be described as a collection of smaller raindroplets, or alternatively, as different interactions from rain asthe water droplet size in fog and cloud is smaller than thewavelength of $3 \mathrm{GHz}$ signals.

The cloud and fog attenuations $\left(A_{c f}\right)$ can be expressed in terms of $\mathrm{RR}_{\mathrm{pr}}$ and propagationangle for a specific frequency and temperature valuest $t_{k}$ (Kelvin), through the following series of equations, culminating into equation (37).

$$
\begin{aligned}
\mathrm{D}_{\mathrm{p} 1} & =\left(\left(\varepsilon_{0}-\varepsilon_{1}\right) /\left(1+\left(f / f_{p}\right)^{2}\right)\right) \\
& +\left(\left(\varepsilon_{1}-\varepsilon_{2}\right) /\left(1+\left(f / f_{s}\right)^{2}\right)\right)+\varepsilon_{2}
\end{aligned}
$$

$$
\begin{gathered}
\mathrm{D}_{\mathrm{p} 2}=\left(f \cdot\left(\varepsilon_{0}-\varepsilon_{1}\right) /\left(f_{p} \cdot\left(1+\left(f / f_{p}\right)^{2}\right)\right)\right) \\
+\left(f \cdot\left(\varepsilon_{1}-\varepsilon_{2}\right) /\left(f_{s} \cdot\left(1+\left(f / f_{s}\right)^{2}\right)\right)\right) \\
\eta=(2+\mathrm{Dp} 1) / \mathrm{Dp} 2 \\
t_{1}=300 / t_{k},
\end{gathered}
$$

where

$t_{k}$ : Temperature (Kelvin)

$$
\varepsilon_{2}=3.51, \varepsilon_{1}=5.48,
$$

and

$$
\begin{gathered}
\varepsilon_{0}=77.6+103.3(\mathrm{t} 1-1) \\
f_{s}=590-1500\left(t_{1}-1\right),
\end{gathered}
$$

and

$$
\begin{gathered}
f_{p}=20.09-142\left(t_{1}-1\right)+294\left(t_{1}-1\right)^{2} \\
K_{t}=(0.819 f) /\left(D_{p 2} \cdot\left(1+\eta^{2}\right)\right)
\end{gathered}
$$

The estimated attenuation due to cloud and fog for a given value is:

$$
A_{c f}\left(\theta, R R_{p r}\right)=\frac{L_{v}(p r) \cdot K_{t}}{\sin \theta} d B
$$

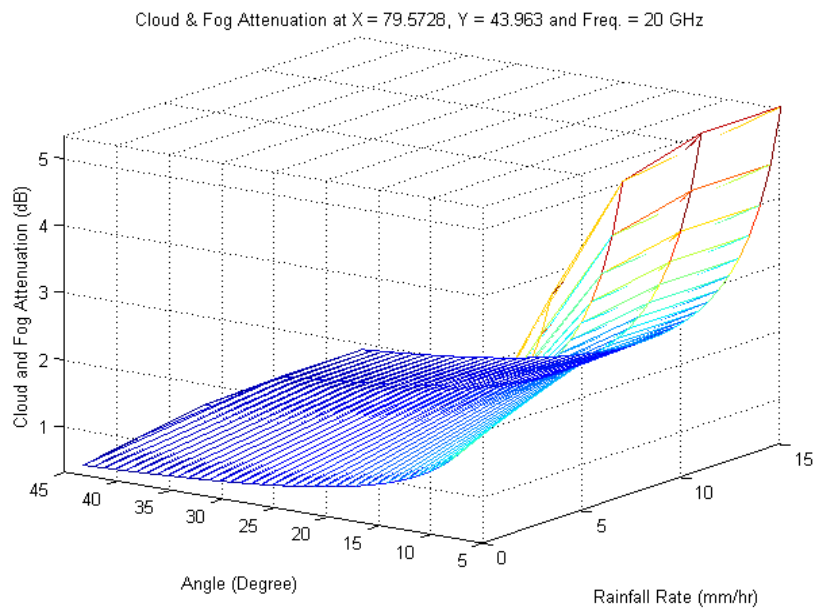

Figure 9. Cloud and Fog attenuations at South West of King City

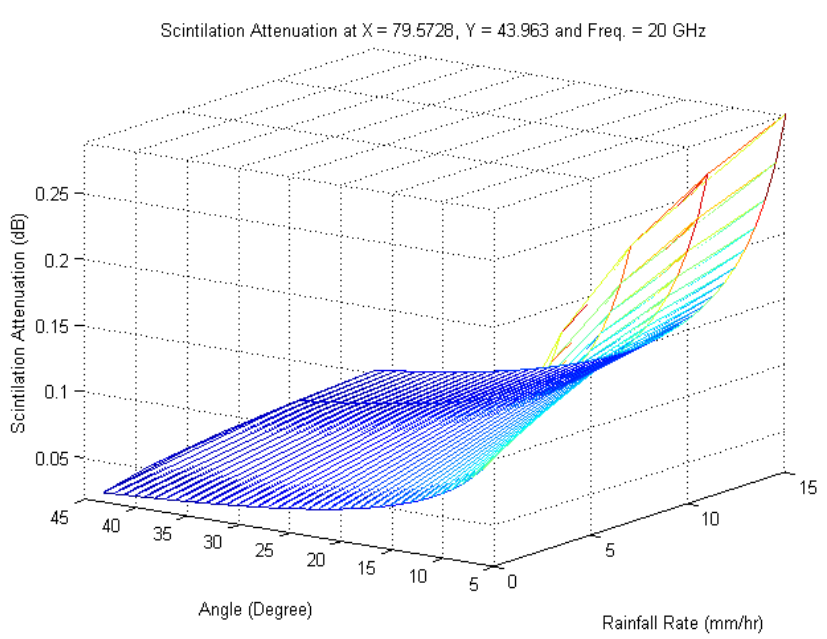

Figure 10. Scintillation attenuation at South West of King City

where $A_{c f}\left(\theta, R R_{p r}\right)$ represent cloud and fog attenuations. $L_{v}$ $\left(\mathrm{kg} / \mathrm{m}^{2}\right)$ is the statistics of the total columnar contentof liquid water. $M\left(\mathrm{~kg} / \mathrm{m}^{3}\right)$ is the integration of liquid water 
density,along a cross section of $1 \mathrm{~m}^{2}$ from surface to topof clouds for a given site. The $L_{v}$ is provided fro m ITU-R for the predicted probability of precipitation $(p r)$ based on $\mathrm{RR}_{\mathrm{pr}}$. Re fer to[5] to obtain the relation between $p r$ and $\mathrm{RR}_{\mathrm{pr}}$. In allpredicted situations the value of $\mathrm{pr}$ is normally found to be in the range of 0.0001 to 0.5 . These attenuations are presentedas a function of $\theta$ and $\mathrm{RR}_{\mathrm{pr}}$ at a station in King City has beenshown in Figure 9.

\subsection{Calculating of Scintillation Attenuation}

The cumulative distribution of tropospheric scintillation isbased on monthly or longer average ambient temperature.This distribution reflects the specific climate condition of thesitd[5],[39]. In satellite communications, scintillation attenuationresults from rapid variations in the signal's amp litude andphase due to changes in the refractive index of the earth's atmosphere.A general technique for predicting this attenuationas a function of $R_{\mathrm{pr}}$ and propagation angle that is greaterthan $4^{\circ}$ is given here.

Calculate the standard deviation of the signal amp litude, $\sigma_{r e f}$ as:

$$
\sigma_{\text {ref }}=3.6 \cdot 10^{-3}+10^{-4} \cdot N_{\text {wet }} d B
$$

where $N_{\text {wet }}$ : radio refractivity, given in ITU-R P. 453.

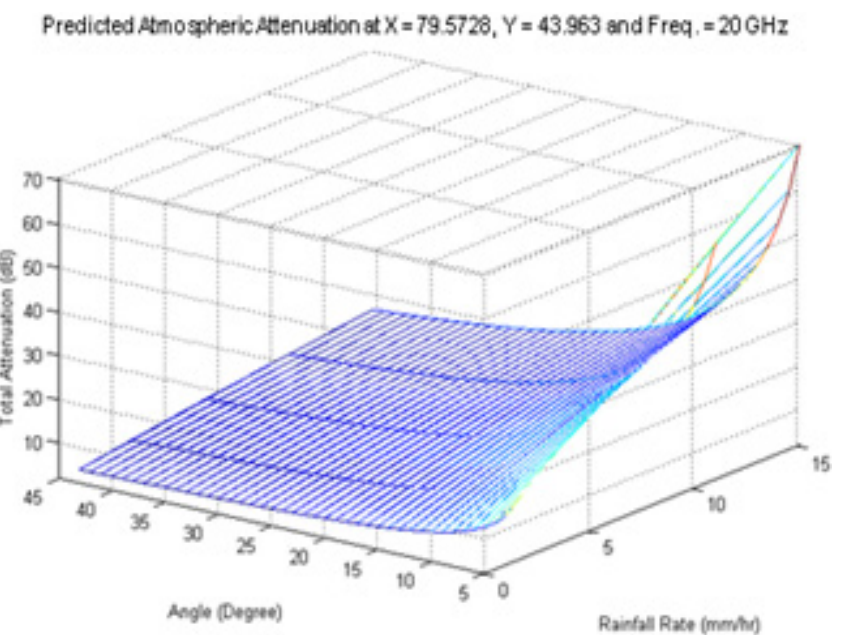

Figure 11. Atmospheric attenuation at South West of King City

Calculate the effective path length $L$ for the height of theturbulent layer $h_{L}$ equal to $1 \mathrm{~km}$ :

$$
L=\frac{2 h_{L}}{\sqrt{\sin ^{2} \theta+2.35 \times 10^{-4}}+\sin \theta} \text { meter. }
$$

Estimate the effective antenna diameter, $D_{\text {eff }}$, from the geometricaldiameter (meter) of the earth-station antenna

$(D)$,and the antenna efficiency $(\eta)$ (with $\eta=0.5$ if unknown), isused as:

$$
D_{\text {eff }}=\sqrt{\mu} \cdot D \text { meter. }
$$

Calculate the antenna aperture averaging factor from:

$$
g(x)=\sqrt{3.86\left(x^{2}+1\right)^{11 / 12} \cdot \sin \left[\frac{11}{6} \arctan \frac{1}{x}\right]-7.08 x^{5 / 6}}
$$

with

and

$$
\sigma(\theta)=\sigma_{r e f} \cdot f^{7 / 12} \cdot \frac{g(x)}{(\sin \theta)^{1.2}}
$$

Calculate time percentage factor, $a(p r)$, for the predictedprobability of precipitation as follows:

$$
\begin{gathered}
\mathrm{a}(\text { RRpr })=-0.061 .(\log (p r))^{3} . \\
\ldots .0 .072(\log (p r)) 2-1.71 \log (p r)+3.0 .
\end{gathered}
$$

Finally, obtain the scintillation attenuation $\left(A_{s}\right)$ from:

$$
A_{s}\left(\theta, R R_{p r}\right)=a\left(R R_{p r}\right) . \sigma(\theta) d B \text {. }
$$

The estimated scintillation attenuation calculated by using(45) on ITU-R data resulted in a set of $A_{s}\left(\theta, R R_{p r}\right)$ values in relation to propagation angle, $R_{\mathrm{pr}}$, frequency, and locationas shown in Figure 10.

\subsection{Calculating Total Attenuation}

The total attenuation $A_{t}$ is made up of two co mponents:

Weather attenuation $(A W)$ and free space attenuation $\left(A_{0}\right)$. The weather attenuation $(A W)$ is calculated from the four constituentattenuations calculated in preceding subsections. Theyare:

1. $A_{r}(\theta, \mathrm{RRpr})$ : rain attenuation, as estimated in (15).

2. $A_{g}\left(\theta, R R_{p r}\right)$ : gaseous attenuation due to water vapourand oxygen, as estimated in (29).

3. $A_{c f}\left(\theta, R R_{p r}\right)$ : cloud and fog attenuations, as estimatedin (39).

4. $A_{s}\left(\theta, R R_{p r}\right)$ : attenuation due to tropospheric scintillation, as estimated in (47).

Given these four attenuations, the total weather attenuation $A_{W}\left(\theta, R R_{p r}\right)$, can be calculated from[5],[8], and[13]:

$$
A_{W}=A_{\text {Gas }}+\sqrt{\left(A_{\text {Rain }}+A_{\text {Cloud \& Fog }}\right)^{2}+A_{\text {Scintillation }}^{2}}
$$

The results with the available measurement data for all latitudesfor the prediction of wide $R_{\mathrm{pr}}$ ranges and propagationangle are shown in Figure 7, Figure 8, Figure 9, Figure 10, and Figure 11.The second component of attenuation is caused by freespace $[36,37]$. We call the loss that occurs in free space freespace attenuation.

Table 3. Antenna Noise temperat ure Ta (Kelvin)

\begin{tabular}{|c|c|c|}
\hline $\begin{array}{c}\text { Directional } \\
\text { satellite antenna }\end{array}$ & Earth from space & $290 \mathrm{~K}$ \\
\hline & Space from earth at & \\
& $90^{\circ}$ elev. & $3-10 \mathrm{~K}$ \\
Directional & Space from earth at & $\approx 80 \mathrm{~K}$ \\
terminal & $10^{\circ}$ elev. & $10^{5} \ldots . .10^{4} \mathrm{~K}$ \\
antenna & Sun $(1 \ldots 10 \mathrm{GHz})$ & \\
\hline Hemispherical & At night & $290 \mathrm{~K}$ \\
terminal & Cloudy sky & $360 \mathrm{~K}$ \\
antenna & Clear sky with sunshine & $400 \mathrm{~K}$ \\
\hline
\end{tabular}

The free space attenuation, $A_{0}(f)$, is obtained as follows:

$$
A_{0}(f)=(4 . \pi \cdot d / \lambda)^{2} \text {, }
$$

Where $d$ is the distance between transmitter and receiver and the wavelength $\lambda=\mathrm{c} / \mathrm{f}$. It would be significant to note that afree space is space with nothing at all in it.

This phenomenondoes not exist in the known universe but interstellar space isa good approximation. The most important four features offree space are its uniformity 
everywhere, absence of electricalcharge, no current flowing through it, and its infinite extent inall directions [40], [41].

That we have obtained atmospheric attenuation and freespace loss, the total attenuation $\left(A_{t}\right)$ can be calculated fromthe following relation:

$$
A_{t}\left(\theta, R R_{p r}\right)=A_{W}\left(\theta, R R_{p r}\right)+A_{0}(f)
$$

Where $A_{t}\left(\theta, R R_{p r}\right)$ is the total attenuation, $A_{W}\left(\theta, R R_{p r}\right)$ is the atmospheric attenuation described in (48)(48), and $A_{0}(f)$ is the free space loss described in (49).

A three dimensional relationship for these attenuations withrespect to propagation angle and $R_{\mathrm{pr}}$ is presented in Figure 12.

These attenuations, for systems running at frequencies above10 GHz- especially those operating with low propagationangles and/or margins, must be considered along with the effectof multip le sources of simultaneous occurring.

This method provides a useful general tool for scaling atmosphericattenuations according to these parameters.

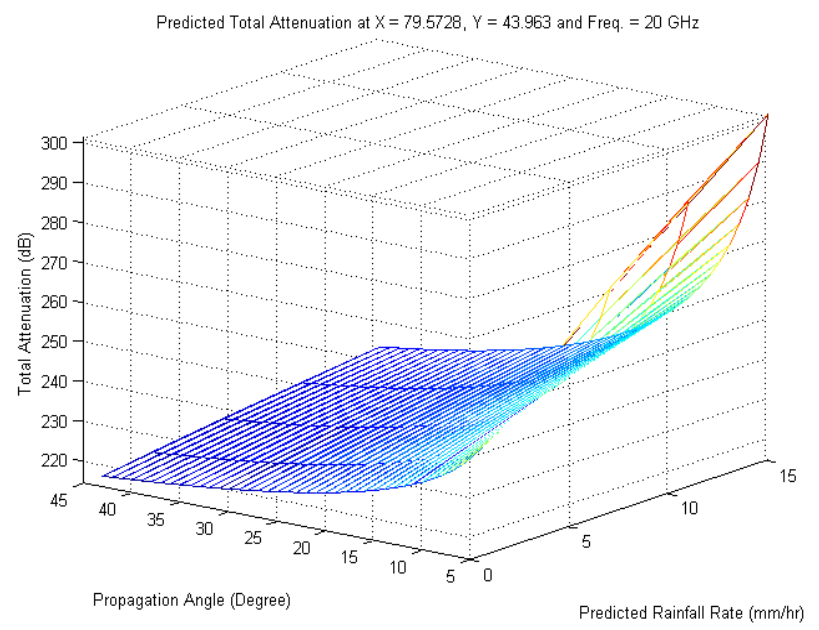

Figure 12. Predicted total attenuation at South West of King City

Also, ithelps to provide designers with a perceptible view of approximateddifferent attenuation values that can be computed at anydesired location, for differentfrequencies, and for wide ranges of $\mathrm{RR}_{\mathrm{pr}}$ and propagation angles.The outcome becomes a key factor in diagnosing, adjustingand improving satellite signal power, modulation and codingschemes, monitored and controlled altogether by a powerfuland efficient intelligent-based attenuation countermeasure system.

We found that practically the prediction of total attenuationobtained in this way is respectable approximation. The totalattenuation is used to calculate SNR, which is then used bythe IWACS in determining channel quality and subsequentlyadjusting satellite propagation parameters as described in thenext section.

\subsection{Relating Total Attenuation with Signal to Noise Ratio (SNR)}

SNR is a measure of signal strength for satellite signal relativeto attenuations and background noise, usually measuredin decibels $(d B)[41]$. The signal energy $\left(E_{s}\right)$ to noise powerspectral density $\left(N_{0}\right)$ per symbol is calculated from the knowledgethat $E_{s}=C \cdot T_{s}=C=R_{s}$, where $C$ is signal power, $T s$ is symbol duration, and $R_{S}$ transmission rate.

$$
\frac{E_{s}}{N_{0}}=\frac{C}{N_{0}} \cdot T_{s}=\frac{C}{N_{0}} \cdot \frac{1}{R_{s}} .
$$

Where thermal noise power spectral density $N_{0}=$ $K_{b}$. T, and $K_{b}$ (Boltzmann constant $)=1.38 .10 \mathrm{e}-23 \mathrm{Ws} / K=$ $228.6 \mathrm{~dB} W \mathrm{~S} / \mathrm{K}$.

$$
\mathrm{T} \text { (effective noise temperature })=\mathrm{T}_{\mathrm{a}}+\mathrm{T}_{\mathrm{r}}
$$

Where $T_{a}$ is noise temperature of the antenna as represented in Table 3 , and

$\mathrm{T}_{\mathrm{r}}$ (nois e temperature of the receiver)

$=\left(10^{\mathrm{Nr} / 10}-1\right) \cdot 290 .(53)$

In the above equation the Noise Figure $\left(N_{r}\right)$ for a low-noiseamplifier is found to be in the range of 0.7 to $2 \mathrm{~dB}$. The aboveequations can now be combined as:

$$
\frac{C}{N_{0}}=\frac{C}{K_{b} \cdot T}=\frac{P_{r}}{K_{b} \cdot T}=\frac{P_{t} \cdot G_{t}}{A_{t}} \cdot \frac{G_{r}}{K_{b} \cdot T}
$$

Where Pt and Pr are trans mitter and receiver power, and $G_{t}$ and $G_{r}$ are antenna gain at transmitter and receiver sides respectively. Therefore,

$$
\begin{gathered}
\frac{C}{N_{0}}=P_{t}+G_{t}-A_{t}+G_{r}-K_{b}-T \\
\frac{E_{s}}{N_{0}}\left(A_{t}, P_{t}\right)=P_{t}+G_{t}-A_{t}+G_{r}-K_{b}-R_{s}
\end{gathered}
$$

It should be noted that the SNR estimation of (54) willbe optimized by the virtue of having better estimation of $A_{t}$ through (56).

\section{Simulation Results and Discussions}

\subsection{Simulation Environment and Implementation}

The mathematical solution for finding any weather attenuationand utilizing that information to improve signal qualityin satellite networks were tested in a simulated system namedIWACS. The system monitors channel qualities and appliescounter measures, which involves controlling of power, frequency,propagation angle, modulation, coding, and data rate.

The outcome is the evolution in signal fidelity, especiallyabove $10 \mathrm{GHz}$, through reduction in digital transmission errors.

In this section, the architecture of the IWACS is brieflymentioned. Details are avoided because the material presentedin earlier section has been the main focus of this article.

The IWACS was simulated in Matlab simulations version7.10.0 running on 17 - 2630QM, 2.00 GHz CPU and6.00 $G B$ RAM. A special module was written to read weatherdata from Environment Canada supplied in aspecially formattedtext stream and converted into a three hour sliding windowof moving weather data always proceeding the present moment.

Software modules were written to extract propagation 
related parameters shown in Figure 5 for the location from ITURsupplied data. Algorithm for predicting the RR based onMarkov theory with fixed-duration weather data was written.

Also, the IWACS used heuristic algorithms that employedfield inputs in problem solving, learning and discovery.The system adhered to formalized knowledge represent ations chemes practiced in the industry, and machine learning techniques, to reach optimal decisionin dealing with different atmosphericconditions [5],[8],[16],[42 ], and[43].The key feature of the IWACS is that it adjusts to signalvariations with a fast response time. In accomplishing this, theemployed technique used feedback of SNR values from thereceiving end of the channel and uses that knowledge to mitigatefuture weather attenuations, thus preventing them fromactually manifest in the channels. This proactive approachto the adjustment of signal characteristics is what makes thesystem meet end-to-end QoS requirements. The core architecture of the IWACS is shown in Figure 13, where it may be noted that it consists of four control blocks, the first control block, the second control block, the third controlblock, and the fourth control block, a feedback loop andcounter iteration, along with a special module called decisionsupport system (DSS). This figure illus- trates the Interrelation-ships of various blocks involved in tuning propagation characteristics of a communication

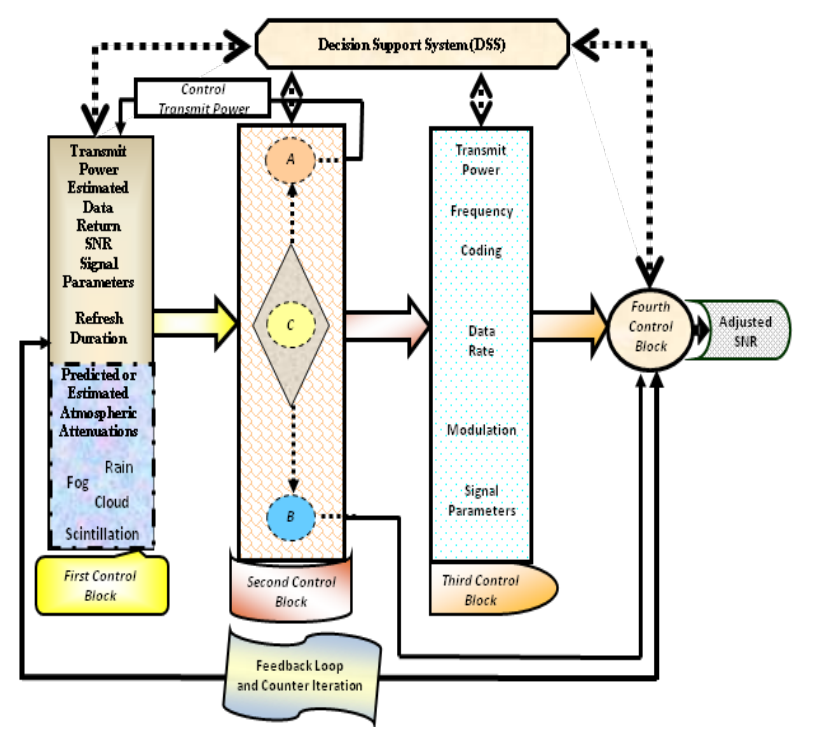

Figure 13. Intelligent weather aware system for satellite net works

The first control block collects vital data like propagationangle, frame size, frequency, transmit signal power, andweather data. Based on these data, it computes atmosphericattenuation and SNR for the following time period. This is where the bulk of the techniques exp lained in earlier sections areemp loyed.

The second control block compares the differences betweenthe estimated SNR and the minimum SNR values sought tomaintain a desired level of QoS, usually set by system's designersbased on experience. These comparisons lead to oneof three different possible outcomes $\{A, B$, or $C\}$ as shown in Figure 13. The first outcome $\{A\}$, is for estimated SNR valuessmaller than the threshold level. In this case the DSS willdecide to increase transmit power up to a maximum limit of $-30 \mathrm{~dB}(0 \mathrm{dBm})$. The second outcome $\{B$, is where estimatedSNR values equal to or exceed the threshold level. TheDSSwill be satis fied and will ju mp to the last block. The thirdoutcome $\{C\}$, is for estimated SNR smaller than the thresholdlevel even after increasing the transmit power to its maximumvalue. The DSS will go to the next block for selecting a combinationof transmission characteristics.

In the third control block, based on adjusted SNR value,the DSS will opt for the adjustment of other para meters suchas data rate, frequency, modulation, and coding values. If thethreshold level value can be reached by using any of the differentvariable combinations, then the DSS will decide to moveto the last block for the final decision. This block emp loysan aid similar to Table 4 in making these decisions, which areprepared based on field experience and expert suggestions.

Table 4. Forward link modes and performance at South West of King City for propagation angle $=45$ Degrees and frequency $=20 \mathrm{GHz}$

\begin{tabular}{|c|c|c|c|c|}
\hline $\begin{array}{c}\text { Modula } \\
\text { tion }\end{array}$ & $\begin{array}{c}\text { LPC } \\
\text { Code } \\
\text { Identifier }\end{array}$ & $\begin{array}{c}\text { Es/N0 } \\
\text { Estimated } \\
\text { Values [dB] }\end{array}$ & $\begin{array}{c}\text { Transmitted } \\
\text { Power } \\
{[\mathrm{dB}]}\end{array}$ & $\begin{array}{c}\text { Weather } \\
\text { Attenuations } \\
{[\mathrm{dB}]}\end{array}$ \\
\hline QPSK & $2 / 3$ & 12.37 & -55 & 214.36 \\
\hline QPSK & $4 / 5$ & 5.90 & -60 & 223.46 \\
\hline 8PSK & $2 / 3$ & 1.2 & -62 & 221.13 \\
\hline 8PSK & $8 / 9$ & 4.86 & -58 & 218.69 \\
\hline 16PSK & $8 / 9$ & 21.10 & -57 & 216.23 \\
\hline
\end{tabular}

The fourth control block interacts with the remote end ofthe channel and determines the current SNR. It then feeds thecurrent SNR value to the input block so that the system's realtimestate is appropriately monitored. This in turn helps toiteratively adjust the channel state.

In case a satisfactory SNR is not achieved through differentcombinations, the control system goes back to first controlblock through feedback and counter iteration block to re-adjustthe parameters (as explained earlier) andcomes to re-work withthe tables according to DSS decision, until a satisfactory valueis reached at which theprocedure will stop. In case significantimprovement is not achieved, the system will abandon the processafter a set number of iterations and gives a warning tothe operator. Whereas, the number of iteration can be set bysystem's designers based on the specific location.

The SNR and other measured parameters are fed to the DSS block to help make the decision to maintain QoSandsatisfy SLAs. The DSS and its network optimization blocksare depicted in Figure 14.

The periodically-computed attenuationkeeps updating the knowledge input to the DSS, which is constructed from specific classes of algorith ms that takesexperiential decision inputs from the user so that they couldbe factored in decision-making activities. Typical informationthat a DSS might gather and present would be: 
a- Accessing current information assets such as knowledgebase, satellite parameters, and triggering of periodicquery

b- Maintaining the database of different combinations ofchannel parameters known to give acceptable system performance.The other blocks can then find the right combinations with the aid of DSS.

Thus, the IWACS minimizes the attenuation effect andmaximizes the channel robustness and efficiency by improvingSNR. Such improvement in turn improves QoS. The ability tobetter predict rain attenuation for different weather conditionsand operational frequencies makes the quest for improved QoSa reality.

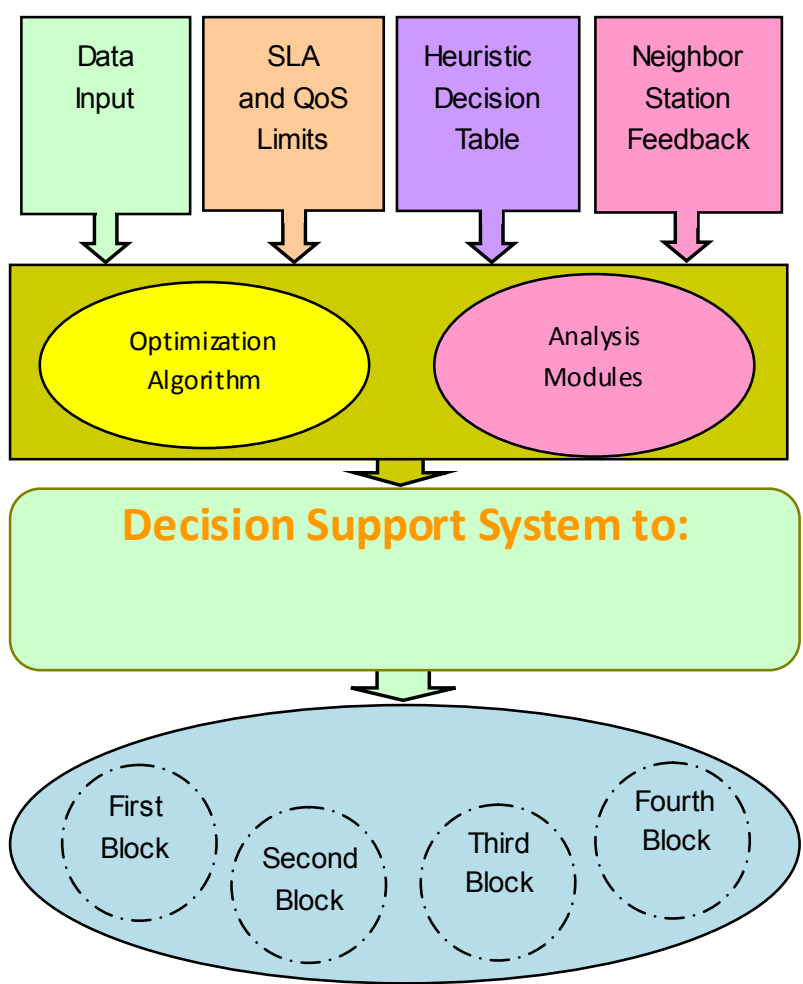

Figure 14. Net work opt imization Decision Support System (DSS)

\subsection{Results}

The system, built on the foundation of the above mentionedprinciples, was found to deliver noteworthy improvements inthe performance of satellite networks.

The system monitored the SNR atthe receiving end of the channels, compared it with a threshold,and searched for a blend of available power, frequency,propagation angle, coding, transmission rate, and modulationin response to predicted channel attenuation. It then attemptedto maintain a desired level of SNR as shown in Figure 12, Figure 13, Figure 14,Figure 15, andFigure 16. Such maintenance required the aid of anexpanded form of Table 4 for selecting the right comb ination of propagation parameters.

Figure 15 and Figure16 compare the SNR before and afterthe techniques discussed in this paper are put to usefor making improved system performance. These figures representcases when SNR fell between $(-39 \sim-16) d B$, and transmit power from $(-100 \sim-88) \mathrm{dB}$ before intelligentdecision mechanism was turned on. The improvementsmade in SNR and transmit power level were significant afterthe IWACS was allowed to operate under the same conditions. The SNR improved to $(5 \sim 27) d B$ and the transmit powerlevel ranged from $(-63 \sim-51) d B$. Both cases were subjectedto identical weather conditions where total attenuationdue to weather rangedfrom $(215 \sim 225) \mathrm{dB}$ for a frequencyof $20 \mathrm{GHz}$ at 40 degree propagation angle. Note that the systemwas able to bring the upper limit of transmit power to lessthan the maximum allowed of $-30 \mathrm{~dB}$. Any time this limitis reached, signal parameters are re-adjusted to prevent uncontrolledsignal transmission as shown in Figure 16and Table 4. Itshould be noted that the improvements in channel performance made by the scheme are significant.

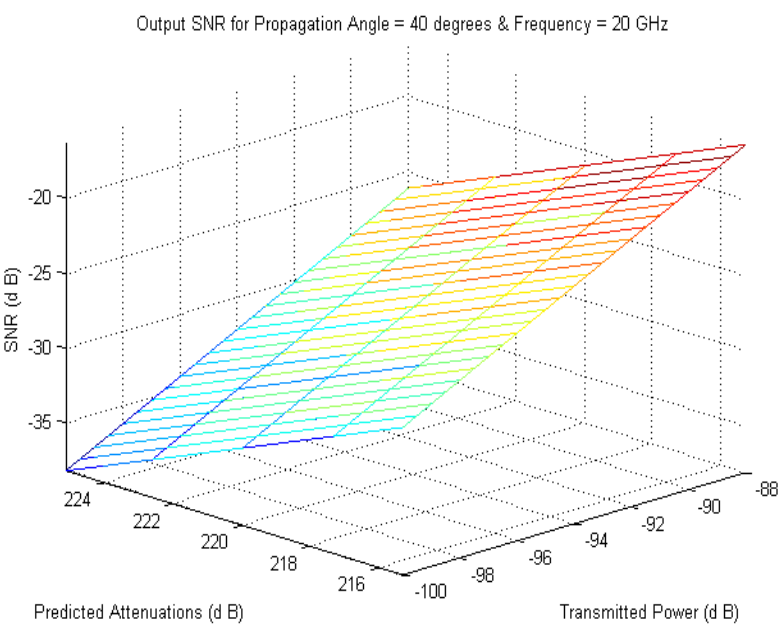

Figure 15. Output SNR at South West of King City channel

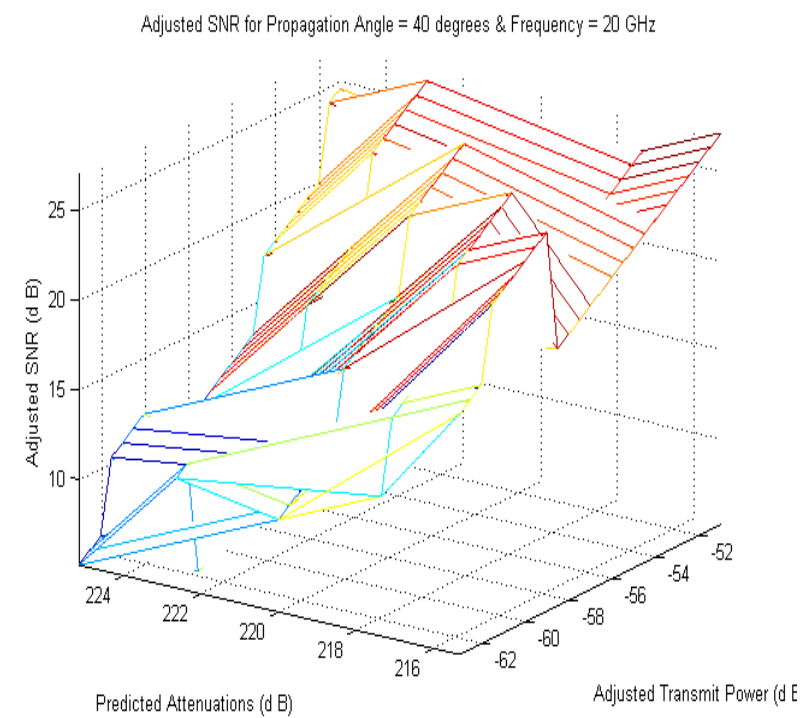

Figure 16. Adjusted output SNR at South West of King City

\section{Conclusions}

Precipitation, gaseous formation, cloud, fog, and scintillationcause attenuation of satellite signals. These attenuationsbecome especially prominent at frequencies 
above Ku band.Such attenuation makes it difficult to provide agreed upon QoSby satellite networks unless special mitigation measures aredevised to counter weather effects. Such control systems couldbe optimized to its most effective status if we had the bestpossible techniques for predicting channel attenuation due toweather related factors. This paper presents a technique forpredicting channel attenuation based on real-time weather dataand the use of the Markov theory. The results thus obtained, arefound to be able to make significant improvement over thetechniques known thus far. This technique positively contributesto QoS maintenance by allowing for better tuning andadaptation of signal propagation parameters such as frequency,power, propagation angle, modulation, coding, and transmissionrate with changing weather conditions. The paper also introducesa three dimensional relationship model between attenuation, propagation angle, and $\mathrm{RR}_{\mathrm{pr}}$ with an implication that for a given atmospheric condition, the signal attenuationcould be predicted with much improved accuracy thanthe techniques known to us. An IW ACS, wh ich controls modulation, coding, transmission power, frequency, propagationangle, and transmission rate to improve channel robustness, isbriefly described. It is believed that the technique presentedhere can be of significant interested to research and developmentcommun ity interest in improving the throughput of satellitenetworks.

\section{ACKNOWLEDGEMENTS}

This work is supported by the Deanship of Scientific Research (DSR)at King Fahd University of Petroleum \& Minerals (KFUPM) through projectNo. JF111005.

\section{REFERENCES}

[1] R. K. Crane, "Prediction of the effects of rain on satellite communication systems," Proc. of the IEEE, vol. 65, pp. 456-474, March 1977.

[2] F. Haidara, A. Dissanayake, and J. Allnutt, "A predictionmodel that combines rain attenuation and other propagation impairments along Earth-satellite paths," IEEE Trans. on Antennas \& Propagation, vol. 45, pp. 1546-1558, Oct. 1977.

[3] ITU-R, Rain height model for prediction methods. Radio wave propagation, International Telecommunication Union. Rec. P.837-4, ITU-R, Fascicle, Geneva, 2001.

[4] D. V. Rogers, L. J. I. Jr., and F. Davarian, "System requirements for ka-band Earth-satellite propagation data," Proc. of the IEEE, vol. 85, no. 6, pp. 810-820, 1997.

[5] K. Harb, A. Srinivasan, B. Cheng, and C. Huang, "Intelligent weather aware scheme for satellite systems," in Proc. IEEE ICC'08, May 2008.

[6] J. Pelton, "The start of commercial satellite communications [History of communications]," IEEE Communications
Magazine, vol. 48, no. 3, pp. 24-31, 2001.

[7] L. J. Ippolito, "Propagation effects and system performance considerations for satellite communications above $10 \mathrm{GHz}$," Proc. of the IEEE, vol. 1, pp. 86-91, Dec. 1990.

[8] K. Harb, F. R. Yu, P. Dakhal, and A. Srinivasan, "Performance improvement in satellite networks based on markovian weather prediction," in Proc. IEEE GlobCom'10, Dec. 2010.

[9] A. A. Aboudebra, K. Tanaka, T. Wakabayashi, S. Yamamoto, and H. Wakana, "Signal fading in land-mobile satellite communication systems: Statistical characteristics of data measured in Japan using ETS-VI," Microwave, Antennas \& Propagation, vol. 146, pp. 349-354, Oct. 1999.

[10] L. J. Ippolito and T. A. Russell, "Propagation considerations for emerging satellite communications ap plications," Proc. of the IEEE, vol. 81, pp. 923-929, June 1993.

[11] L. Mathy, C. Edwards, and D. Hutchison, "Principles of QoS in group communications," Telecommunication Sy stems, vol. 11, no. 1-2, pp. 59-84, 1999.

[12] ITU-R, "Attenuation due to clouds and fog," Radio wave propagation, International Telecommunication Union Recommendation ITU-R P.840-3, 1999.

[13] K. Harb, A. Srinivasan, B. Cheng, and C. Huang, "Prediction method to maintain QoS in weather impacted wireless and satellite networks," in Proc. SMC, Oct. 2007.

[14] ITU-R, Specific attenuation model for rain for use in prediction methods. Radio wave propagation, International Telecommunication Union. Rec. P.838-3, ITU-R, Fascicle, Geneva, 2003.

[15] K. Harb, F. R. Yu, P. Dakhal, and A. Srinivasan, "A decision support scheme to maintain QoS in weather impacted satellite networks," in Proc. AIAA Atmospheric and Space Environments Conference'10, (Toronto, ON, Canada), Aug. 2010.

[16] Telesat Canada, "ISS (Intelligent Satellite Service) Research and Development." website: http://www.telesat.ca, last accessed date March 2012.

[17] J. S. Mandeep, Y. Y. Ng, H. Abdullah, and M. Abdullah, "The study of rain specific attenuation for the prediction of satellite propagation in Malaysia," Journal of Infrared, Millimeter and Terahertz Waves, vol. 31, no. 6, pp. 681-689, 2010 .

[18] ITU, "Radio communiation sector (ITU-R) home." website: http://www.itu.int/ITU-R, last accessed date April 2012.

[19] K. Harb, A. Srinivasan, B. Cheng, and C. Huang, "QoS in weather impacted satellite networks," in Proc. IEEE Pacific Rim Conference on Communications, Computers and Signal Processing, (Victoria, B.C., Canada), Aug. 2007.

[20] C. I. Christodoulou, S. C. Michaelides, M. Gabella, and C. S. Pattichis, "Prediction of rainfall rate based on weather radar measurements," in International Joint Conference on Neural Networks IJCNN, (Budap est, Hungary), July 2004.

[21] J.-C. Hsieh, H.-P. Lin, and C. Yang, "A two-level, multistate markov model for satellite propagation channels," Proc. IEEE VTC, vol. 4, pp. 3005-3009, May 2001.

[22] J. A. Garcia-Lopez, J. M. Harnando, and J.M. Selga, "Simple 
rain attenuation prediction method for satellite radio links," IEEE Trans. on Antennas \& Propagation, vol. 36, pp. 444-448, March 1988.

[23] U. C. Fiebig, "Modeling rain fading in satellite communications links," in Proc. IEEE VTC'99, vol. 3, pp. 1422-1426, Sept. 1999.

[24] E. E. Altshuler, M. A. Gallop, Jr., and L. E. Telford, "Atmospheric attenuation statistics at 15 and $35 \mathrm{GHz}$ for very low elevation angles," Radio Science, vol. 13, no. 5, pp. 839-852, 1978.

[25] S. D. Slobin, "Microwave noise temperature and attenuation of clouds: Statistics of these effects at various sites in the United States, Alaska and Hawaii," Radio Science, vol. 17, no. 6, pp. 1443-1454, 1982.

[26] L. Saloff-Coste, Lectures on finite Markov chains. In Lectures on probability theory and statistics (Saint-Flour, 1996), vol. 1665. Springer, Berlin, 1997.

[27] V. Network, "Bilinear interpolation definition." website: http://www.pcmag.com/ency clopedia-term/0,1237,t=bilinear +interpolation\& $\mathrm{i}=38607,00$.asp, last accessed date $\mathrm{March}$ 2012.

[28] R. McLeod and M. L. Baart, Geometry and Interpolation of Curves and Surfaces. Cambridge University Press, July 1998.

[29] D. A. Sanchez-Salas and J. L. Cuevas-Ruiz, "N-states channel model using Markov Chains," Proc. of Electronics, Robotics and Automotive Mechanics Conference, pp. 342 - 347, Oct. 2007.

[30] W. Suozhu, L. Haifang, and H. Zhaohui, “Application of Markov Chains prediction model in product layout optimization," International Forum on Computer Science-Technology and Applications (IFCSTA)'09, vol. 3, no. 10, pp. 243-246, 2009.

[31] V. Network, "VSAT network types." website:http://www.comsys.co.uk/wvm mn.htm, last accessed date Feb. 2012.
[32] K. M. S. Murthy, J. Alan, J. Barry, B. G. Evans, N. Miller, R. Mullinax, P. Noble, B. O’Neal, J. J. Sanchez, N. Seshagiri, D. Shanley, J. Stratigos, and J. W. Warner, "VSAT user network examples," Communication Magazine, vol. 27, pp. 50-57, May 1989.

[33] D. Chakraborty, "VSAT communications networks - An overview," Communication Magazine, vol. 26, pp. 10-24, May 1988.

[34] L. P. Seidman, "Satellites for wideband access," Communication Magazine, vol. 34, pp. 108-111, Oct. 1996.

[35] ITU-R, Propagation data and prediction method required for the design of Earth-space Telecommunication systems. Radio wave propagation, International Telecommunication Union. Rec. P.618-7, ITU-R, Fascicle, Geneva, 2001.

[36] L. A. Hoffman, H. J.Wintroub, and W. A.Garber, "Propagation observations at 3.2 millimeters," Proc. of the IEEE, vol. 54, pp. 449-454, June 2005.

[37] K. Harb, F. R. Yu, P. Dakhal, and A. Srinivasan, "An intelligent QoS control system for satellite networks based on markovian weather," in Proc. IEEE VTC'08, Sep. 2010.

[38] Y. Karasawa, K. Yasukawa, and M. Yamada, "Tropospheric scintillation in the 14/11-GHz bands on Earthspacepaths with low elevation angles," IEEE Trans. onAntennas \& Propagation, vol. 36, pp. 563-569, March1988.

[39] G. Maral and M. Bousquet, SatelliteCommunicationsSystems. John Wiley \& Sons Ltd, UK, 1993.

[40] E. Lutz, M. Werner, and A. Jahn, Satellite Systems forPersonal and Broadband Communications. Springer,New York, 2000.

[41] Y. Leung, Intelligent spatial decision support systems.Springer Verlag, New York, 1997.

[42] L. J. Bannon, "Group decision support systems: An analysis and critique,'In Proceedings of 5th European Conference on Information Systems, pp. 526-539, June 1997. 